\title{
THE
}

\section{Writing With(out) Pain: Computing Injuries and the Role of the Body in Writing Activity}

Kim Hensley Owens

University of Rhode Island, okhensley@uri.edu

Derek van Ittersum

Follow this and additional works at: https://digitalcommons.uri.edu/writing_facpubs

The University of Rhode Island Faculty have made this article openly available.

Please let us know how Open Access to this research benefits you.

This is a pre-publication author manuscript of the final, published article.

Terms of Use

This article is made available under the terms and conditions applicable towards Open Access Policy Articles, as set forth in our Terms of Use.

\section{Citation/Publisher Attribution}

Ownes, Kim Hensley \& Van Ittersum, Derek. Writing with(out) pain: Computing injuries and the role of the body in writing activity. Computing and Composition, vol. 30, no. 2, 2013, pp. 87-100.

Available at: http://dx.doi.org/10.1016/j.compcom.2013.03.003 


\begin{abstract}
This article uses the lens of computer writing injuries to explore writing as an embodied activity. We use philosopher Mark Johnson's five-part definition of embodiment to develop an analysis that examines the physical, flesh-and-blood aspects of writing in addition to the social and cultural aspects of embodied activity. With this framework, we show the limits of purely technological solutions to writing injuries (like ergonomic keyboards) and explore the difficulties of including somatic training in the writing classroom. Rather than prescribing a single solution, we propose that these injuries require multifaceted infrastructural changes, and point to the benefits of approaching writing with mindfulness. We conclude by suggesting ways that writing instructors and scholars can use this framework to rethink the role of the body in writing activity.
\end{abstract}

\title{
Acknowledgements
}

Special thanks to Kristie Fleckenstein, Christina Haas, Gail Hawisher, Peter Mortensen, Brad Peters, Janine Solberg, Amy Wan, and the anonymous reviewers for providing valuable feedback at various stages of this project.

\section{Writing with(out) Pain:}

\section{Computing Injuries and the Role of the Body in Writing Activity}

The basis of all our forms of understanding is that given to us by our body's interactions with the world. Somatic

understanding precedes all others, and persists while our symbolic forms of understanding develop, and it shapes those forms of understanding in profound and subtle ways. Understanding human cognition, then, requires our careful 
attentiveness to the body that is their foundation. We have attended to the body's role in our cultural lives and especially in education far too little. -- Kieran Egan (2004, p. ix)

\section{Studying Bodies vs. Embodied Studies}

In "Rewriting Identity," Jabari Mahiri and Amanda J. Godley (1998) describe the struggles of a Latina college senior, Viviana, who develops carpal tunnel syndrome while transcribing interviews at a computer for a summer job. A "highly literate" young woman whose identity is inextricably linked with her literacy, Viviana's sense of self is tremendously challenged by debilitating pain that prevents her from writing. The authors conclude the study with hopes that voice recognition software could eventually help writers avoid the repetitive hand movements that cause such pain. Kim Hensley Owens (2010) problematizes that quickfix hope for voice recognition software in "'Look Ma, No Hands." When experiencing debilitating hand and wrist pain, diagnosed as tendonitis, Owens confronted a challenge to her sense of self similar to Viviana's, turning to voice-recognition software, which did not live up to the high hopes those like Mahiri and Godley have for the technology's potential to help injured writers. Owens laments that writing had begun to prevent her from writing: "That writing, which I have always found to be liberatory and essential to my self-definition, could cause me to lose the ability not only to write, but to perform the most basic tasks of self-care, is profoundly disturbing" (np).

These two troubling cases represent a small fraction of the rising rate of injuries attributed to writing and/or computer use. ${ }^{1}$ A 2000 article in the American Journal of Medicine reports that

\footnotetext{
${ }^{1}$ We use the term "writing" in this article where some readers might expect to see "keyboarding" or “computing." We do so for two reasons: 1) writing injuries are not tied exclusively to computers, but to issues of
} 
"[m]ore than half of the undergraduates at [the researcher's] university reported having upper extremity symptoms while using the computer, and one in eight people reported symptoms after computing for an hour or less" (Katz et al., 2000, p. 584). A 2005 study reported similar results among American college women (Hamilton, Jacobs, \& Orsmond, 2005). In their review of six English-language studies of computing postures, Gerr, Marcus, and Monteilh (2004) found that in populations other than college students, rates of injury due to computing are also high. These alarming figures and the distressing stories of writers like Viviana and Owens, we believe, challenge scholars in computers and writing, and rhetoric and composition more broadly, to attend carefully to the bodies of writers - our own and those of our students.

Much of the work in our field that describes or relates to bodies focuses on bodies as epistemological sites (Selzer \& Crowley, 1999). Such valuable work describes how bodies are marked and viewed — as gay or straight (Hudson, 2007; Malinowitz, 1995), literate or illiterate (Mortensen, 1999), contained or messy (Birmingham, 2004), temporarily able-bodied or disabled (Brueggemann, White, Dunn, Heifferon, \& Johnson Cheu, 2001; Price, 2007; Wilson \& Lewiecki-Wilson, 2001). Scholars can turn to pieces about how different bodies inhabit spaces (Kaufman, 2007), how a body's performed gender affects it as a teacher or a student (Kazan, 2007), how a body's presence or absence matters in a digital environment (Hayles, 1999). Our field also provides a rich array of literature about where and under what external circumstances

repetitive motion and bodily positioning that can be damaging with any type of writing (or other) technology, including pen/cil and paper, and 2) while people use computers for far more than writing, writing in the US today is typically inextricable from computers. Further, when examined infrastructurally, any discussion of bodily practices or injury developed through any computer use affects and is connected to all computer use, including, of course, writing. Key to our argument is that writing scholars and teachers can affect bodily practices and help to prevent writers from inducing physical harm while writing. 
bodies write (Brodkey, 1996; Fleckenstein, 1999; Gere, 1994; Prior \& Shipka, 2003; Reynolds, 2004). While this range of citations suggests there is much in the field of rhetoric and composition about bodies, there is very little in the way of descriptions, analyses, theories of or advice for the bodies of writers as they write.

Scholars within rhetoric and composition have already drawn attention to some aspects of writers' bodies, yet they have typically avoided discussions of physical bodies writing. "We are our bodies; we are writing bodies", Kristie Fleckenstein (1999, p. 29) correctly insists. Fleckenstein shares the concept of the "somatic mind" to describe bringing the body to the workings of the mind. She brings attention to particular bodily aspects of writing, including the bodily experience of writing with one's small children in the room. And yet while her article has much to do with acknowledging the body in our writing and examining how we write ourselves into bodily understandings, an important task, it has less to do with considering how bodies actually write. In Embodied Literacies, Fleckenstein suggests that "we can teach to the health of the individual and the health of the community," and that "[t]eaching (or not teaching) literacy directly implicates the spiritual, psychological, and physical health of the citizenry, and of the community as a whole" (47). We agree. And we take Fleckenstein's claims about writing bodies and the value of our discipline to students' health a step further: students' health cannot benefit from the practice of literacy if the practice of literacy is itself damaging to their health. The practice of literacy involves repetitive bodily interactions with a variety of technologies (from pencils to pixels, with a nod to Dennis Baron), and as we begin to demonstrate in this article, that practice carries risks. Like Fleckenstein, we believe that we can "teach to the health" of our students; further, we believe doing so includes explicit attention to how students use their bodies as they write. 
Our field does not yet have an explicit understanding of the ways the movements and presence of the body of a writer are important. We can, however, begin to see these connections emerging in the field if we turn, for example, to a study of the ways college athletes' bodily knowledge isn't, but might be, taken up in writing classrooms (Cheville, 2001), or to an examination of how particular embodied activities were intertwined with the teaching of rhetoric in ancient Greece (Hawhee, 2004). In this article, we explore the physicality of writing and the physical act of writing through the lens of writing injuries. Drawing on Mark Johnson's (2008) five-part definition of embodiment, we seek to add discussion of the biological, ecological, and phenomenological aspects of embodiment to the rich scholarship of social and cultural embodiment already present within rhetoric and composition. We believe the particular challenges of writing injuries require our attention as computers and writing scholars and writing teachers more generally, but what is ultimately at stake is an understanding of writing activity as embodied in many different ways. A more expansive view of embodiment offers a means of responding to the challenge of writing injuries and also points to new avenues of inquiry, such as the role and effects of body positioning and movement on writing activity or the management and effects of physical energy levels while writing.

\section{Embodiment in Composition}

We want to argue, along with Sharon Crowley (2002), Kristie Fleckenstein (1999, 2003), and Christina Haas and Steve Witte (2001) that greater attention should be paid within our discipline to the role of embodied activity in writing. Even in studies that make reference to embodiment or explore the connections between mind and body, Haas and Witte argue, "the authors do not address the embodied nature of writing directly or explicitly" (p. 415). Yet, as they show, bodily activity plays a crucial role in writing practices: "in labeling writing an embodied practice, we 
mean that its recurrent nature, its goal directedness, and its intimate linking with technologies and with knowledge are always enacted in part through bodily and sensory means" (p. 416). Haas and Witte are primarily concerned with detailing the ways embodied knowledge and physical activity such as gestures play a significant, inextricable, role in writing activity and particularly technical writing. Our project builds on their insightful analysis of these embodied aspects of writing, but takes a different focus: namely, attending to the varied relationships between writers' bodies, writing tools, and writing practices.

This article traces the circumstances in which bodies must come to mind for writers: when writing causes bodies pain. Pain is not, of course, the sole reason people come to consider their bodies as they write, but it is a common one. We acknowledge that writing and pain have different connotations in different situations and cultural contexts; writing has been demonstrated to help alleviate emotional pain (Harris, 2003; Pennebaker, 1990), for example, and learning to read and write has caused intertwined physical and emotional pain (Brandt, 2001). It is also worth noting that "pain" can be valued by some as a necessary means to an end (such as for athletes and dancers), or its appearance and acknowledgment an expression of weakness, or its very existence denied for certain populations, such as, historically, babies (Chamberlain, 1998) and African Americans.

One way to understand these varied perspectives on pain is through philosopher Mark Johnson's (2008) multidimensional definition of embodiment. The first dimension is "The Body as Biological Organism," which includes the "flesh-and-blood body" but also "the preconscious capacities for bodily posture and movement" as well as "emotions and feelings" (p. 164). Swollen wrists, hunched shoulders, and feelings of frustration due to voice-recognition technologies all involve this dimension. "The Ecological Body," the second dimension, posits the 
body and its environment not as separate entities but "as aspects of one continuous process" where human development in inseparable from the "organism-environment couplings" (p. 165). Human bodies that sit in chairs for prolonged sessions over many days develop shortened psoas and hamstring muscles in the legs, leading to stiffness and pain while writing. The "body as we live and experience it" (p. 165) constitutes the third dimension, or "The Phenomenological Body." This dimension includes more than just "our conscious awareness of our bodily comportment and structure" but also the "pre-reflective, nonconscious structures that make it possible for us to have any bodily awareness" (p. 165). It is difficult to describe pain at this dimension; as Elaine Scarry (1985) asserts, "Whatever pain achieves, it achieves in part through its unsharability, and it enures this unsharability through its resistance to language" (p. 4). Body awareness training (e.g., yoga, the Alexander Technique, the Feldenkrais Method) often works to help people experience this dimension of embodiment in conscious ways. Johnson's fourth dimension is "The Social Body," which includes the ways "our bodies develop in and through our inter-personal dialogical relations with our social others" (p. 165). Postures and interactions with technologies, including those that lead to pain, are learned in part through observation of and physical interactions with other people in social settings. Lastly, "The Cultural Body," centers on the ways "our bodies are constituted also by cultural artifacts, practices, institutions, rituals, and modes of interaction that transcend and shape any particular body and any particular bodily action" (p. 165). Besides the more obvious ways race, class, and gender shape embodiment in this dimension, it also refers to the work of government institutions or medical organizations when they classify and define a painful condition or bodily action.

Johnson argues that in everyday life we tend to privilege the first dimension of embodiment, while ignoring the social and cultural levels. At the same time, he suggests that "the postmodern 
literary theorist tends to focus too exclusively on the cultural fashioning of the body" thereby leaving "out many of the sources of, and constraints on, meaning and mind that come from the character of our corporeal rootedness in the biological-ecological processes of life" (p. 166, cf. Hayles, 1999). We aim to avoid both extremes in our examination of writing pains. Too many of the accounts of embodiment in English studies have privileged one or two of these dimensions at the expense of the others - primarily through ignoring the first three dimensions. The cultural practice of writing (or any artistic expression) as a means to relieve emotional pain is well known, but at the same time people who want to write their way out of emotional pain cannot do so if the physical practice of writing is too painful at a phenomenological or flesh-and-blood level because of carpal tunnel or similar afflictions (e.g., Viviana's and Owens' experiences).

We begin the next section at the biological and ecological dimensions of embodiment by tracing the relationships between physical writing practices, writing technologies, and painful conditions. After examining the causes, definitions, and different ways of naming writing-related injuries $^{2}$, we look at several technologies designed to alleviate or prevent writing pain. We suggest that writing technologies are at once a cause and solution of writing pain and describe an attempt at somatic instruction geared to help students prevent future injury.

\section{Writing bodies in pain}

The body is man's [sic] first and most natural instrument.

Or more accurately, not to speak of instruments, man's

\footnotetext{
${ }^{2}$ Because of the dominance of computer technology as the primary means of writing for many people, we will focus our analysis of writing pain on the particular ailments computer users face. However, most widespread writing technologies have led to their own particular set of aches and pains. Allard Dembe (1996) quotes a 1713 account by Bernardino Ramazzini of "failure of power in the right hand" of clerks due to "incessant driving of the pen over paper" (p. 27). The upgraded steel nib pen also led to a kind of cumulative trauma disorder (Tenner, 2003, p. 197).
} 
[sic] first and most natural technical object, and at the

same time technical means, is his body.

--Marcel Mauss (2007)

Physical pain due to writing, despite its long history in the form of scrivener's palsy, writer's cramp, and other ailments (cf. Dembe, 1996) remains something of an invisible problem-both in the field of Rhetoric and Composition and in the culture at large. Elaine Scarry (1985) has argued that pain is "that which cannot be confirmed" (p. 4). Certain external signs may alert us to a colleague or friend in pain, such as wrist braces or ergonomic keyboards, but for the most part, the physical presence or experience of these pains remains verbally and physically unshareable. Beyond what Scarry identifies as the inarticulability of pain is the variety of cultural or social reasons for hiding pain, and the masking of such pains by absencing any evidence of them in the workplace: for example, the Occupational Safety and Health Administration (OSHA) in the United States no longer includes a category for cumulative trauma disorders on its forms for reporting workplace injuries (Jain, 2006, p. 86). OSHA's category discontinuation is one example of a cultural silencing of pain.

However ultimately unshareable, whether by dint of lack of language, lack of official recognition, or a variety of other reasons, writing pain can be made somewhat more visible through the lens of anatomy, one means of approaching the biological dimension of embodiment. Technology historian Edward Tenner (1997) notes that in typing, "the nine flexor tendons that control the movement of the fingers of each hand are bunched in an opening surrounded by the eight carpal bones of my wrist, which are connected by a strong ligament. Through this tube, called the carpal tunnel, the median nerve also connects with the hand's sensory cells" (p. 221). As Tenner explains, repetitive hand movements required for typing cause fluid to build up 
around the tendons as a kind of protective measure. However, this fluid presses on the median nerve in the carpal tunnel, causing pain and numbness, and possibly chronic injury. Tenner's evocative description illustrates but one avenue for injury in the wrist from typing; other components, too, can become strained and inflamed. One researcher found that a poorlydesigned keyboard required about 35,000 additional pounds of force per day to use (compared to the American National Standards Institute [ANSI] standards for such designs) — force that affects the "fingertips, fingers, hands, and arms" (qtd. in Jain 91). Although carpal tunnel syndrome functions metonymically for all writing pain in the social imaginary, not all pain in the wrist and hand is due to this particular physical condition (and cannot be solved by the pervasive surgical response to CTD [cf. Dembe, 1996]). Additionally, besides those in the wrist and hand, many other aches and pains trouble writers today (and have troubled those in the past), including in the neck, lower back, and shoulders.

Recent American studies of typing pain—which has been given numerous labels including cumulative trauma disorder (CTD), repetitive stress injury (RSI), and work-related upper limb disorders (WRULD) — have reported a sharp increase in the numbers of people afflicted during the 1990s, with incidence rates continuing through the previous decade (Robertson et al., 2009). A 2002 study of newly hired computer users found that more than $50 \%$ reported musculoskeletal pain symptoms within their first year of work (Gerr et al., 2002). Clearly computer use, and by extension contemporary writing, can be a dangerous activity.

The specific dangers of computer use are still being explored by occupational health researchers and ergonomists, who tend to focus on objects like keyboards. But writing pain is not, as might be assumed, caused solely by a specific keyboard design, a specifically flawed body, or one particular posture. As Johnson's five levels of embodiment suggest, pain itself is 
not experienced at only an anatomical dimenson; as such, writing pain cannot be best prevented, solved, or theoretically addressed without considering the full infrastructure of composing, the always emerging network of actors that participate in composition (cf. DeVoss, Cushman, \& Grabill, 2005). Keyboards and furniture play a role, surely, but so do our bodily practices, attitudes, culture, and tasks. In the next section, we describe the inadequacy of ergonomic solutions to writing pain, which focus on single or isolated symptoms rather than addressing the fuller infrastructures of composing.

\section{Technologies assisting bodies}

Writing pain is often assumed to be caused by writing technologies, and technological solutions are often sought first and imbued with significant hopes, as Mahiri and Godley (1998) demonstrate with their voice recognition software. Yet while ergonomic purchases seem wise and full of pain-free promise, when incorporated in an unhealthy infrastructure that discourages writers from attending to their bodies, these ergonomic objects may not alleviate symptoms completely or indefinitely. In a consumerist society such as ours, the purchase of a discrete item, such as an ergonomic keyboard, presents a more straightforward choice for alleviating pain than a more open-ended somatic approach incorporating the biological, ecological, and phenomenological dimensions, which might include yoga, frequent breaks, and/or attention to posture and movement while writing.

In an attempt to avoid keyboard-related pains, some writers turn to voice recognition software to avoid the finger-key interaction altogether (with mixed results; see Honeycutt, 2003; Owens, 2010; Pogue, 2006). Most, though, seek to improve, rather than sever, the relationship between body and keyboard. Second Author, like many heavy computer users experiencing pain, turned initially to an ergonomic keyboard and a trackball. Others turn to wrist braces or a 
different, ergonomic chair. ${ }^{3}$ These objects aim to put the body into a different, ostensibly more healthy, posture. In effect, these objects discipline bodies by requiring specific body positions. Although the disciplining function of these objects is intended to be "good for you," like eating one's vegetables, before submitting to this discipline it's worth exploring the history of these objects' designs and their designers' motivations. Recent research, as we will show below, questions many of the assumptions made material in common designs of ergonomic keyboards, such as split keyboards.

Ergonomists have long argued that the harmful postural demands of typing, like "ulnar deviation, wrist extension, forearm pronation, and shoulder abduction, are related to the design of the conventional, straight keyboard" (Rempel, 2008, p. 385). As far back as 1915, keyboard designers have experimented with split keyboards as a way to avoid these postural demands. The split keyboard design most familiar to American consumers is likely that offered by Microsoft since 1994, a frequently studied model. The Microsoft Natural Elite keyboard was the only split keyboard of a group of three that alleviated symptoms for injured users over the entire duration of a six-month study (Tittiranonda, Rempel, Armstrong, \& Burastero, 1999). The length of the study was crucial, since even a conventional keyboard used as a placebo alleviated symptoms for up to 12 weeks. An updated 2007 study used electronic sensors to precisely measure posture in participants typing with a number of split and conventional keyboards (Rempel, Barr, Brafman, \& Young, 2007). That study found that the Microsoft Natural Elite provided a generally neutral typing posture with regards to the wrist and forearm. Both the 1999 and 2007 studies proposed neutral postures as safe for typing because they eliminated the dangerous wrist, arm, and

\footnotetext{
${ }^{3}$ For a fascinating critical history of the physical problems and power relations linked to the use of chairs, see Galen Cranz (1998), The Chair.
} 
shoulder positions listed by Rempel above. However, neutral posture alone, enforced by any keyboard - an isolated element in the infrastructure of composing — has not been proven to eliminate chronic pain conditions like RSI and CTD.

While traditional split keyboard designs attempt to affect typists' postures, other designs, such as the Kinesis Contoured keyboard (Fig. 1), rely on more dramatic design differences to force a neutral posture.

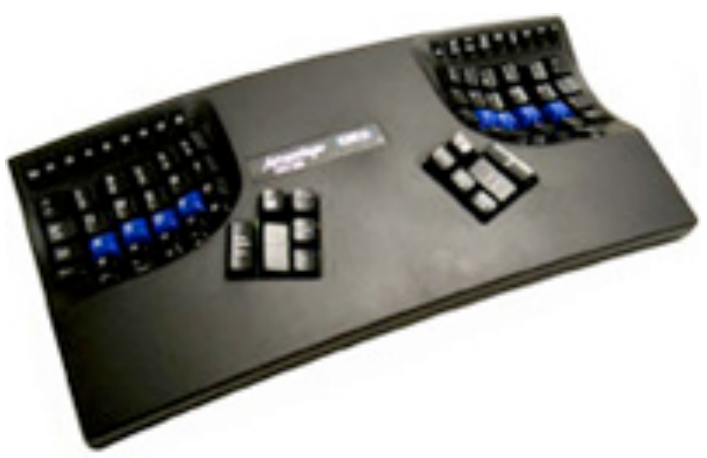

Fig 1. Kinesis Contoured Keyboard (source: http://www.kinesis-ergo.com/contoured.htm) According to Kinesis' promotional materials, the design is intended to reduce ulnar deviation, forearm pronation, and wrist extension (http://www.kinesis-ergo.com/benefits.htm), all identified by Rempel as harmful and caused by traditional keyboard designs (2008, p. 385). Furthermore, the concave key wells allow the hands to "reach into" the keyboard, and the entire design is narrower than traditional keyboards, bringing the mouse or trackball within reach. A 1994 study used EMG readings to determine that the keyboard required less muscular force both in typing and in rest (Gerard, Jones, Smith, Thomas, \& Wang, 1994). ${ }^{4}$

\footnotetext{
${ }^{4}$ Incidentally, the researchers also found that typists experienced on conventional keyboards could gain up to $70 \%$ of their top speed with the Kinesis in about two hours.
} 
With its unique design, the Kinesis keyboard functions similarly to many modern technologies by subtly disciplining human behavior; in this case, by forcing certain parts of the body into a specific posture. Bruno Latour provides many examples of this function of technology, referring to the way people delegate rules for behavior to machines and devices. He describes the design of his file cabinet that only allows one drawer to be open at a time, since opening two drawers at once would likely lead the whole cabinet to tip forward. Latour says he is "obliged" by the mechanical functions to follow this "moral" law of the cabinet (2002, p. 253). As much as he might like to have all three open and risk the danger, the device does not allow it. Like the cabinet, the Kinesis keyboard requires compliance with certain rules. Ad copy from the brochure makes these requirements explicit with active verbs: "Concave keywells place hands in relaxed and neutral position"; "True split retains arms in natural forward position.” A person who might prefer or require different arm or hand placement will be thwarted by the keyboard.

Although the Kinesis designers appear to have keyboard users' best interests in mind when creating these requirements, it is not clear whether the postural demands of the Kinesis, or any current ergonomic keyboard, can prevent or relieve writing pain. A 2006 review of Englishlanguage literature on ergonomic interventions in office workplaces identifies inconsistent findings, reporting that "the current state of the peer reviewed literature provides relatively few high quality studies of the effects of office ergonomic interventions on musculoskeletal or visual health" (Brewer et al., 2006, p. 356). One study finds challenges with methodologies for determining what postures or habits actually cause work-related injuries in office settings (Gerr et al., 2004). Too many studies, they argue, are based on observations after a worker reports pain; such studies may assume that the observed worker's postures and habits caused pain when it could also be true that workers in pain may have only adopted those observed postures or 
habits as a response to that pain. To redress methodological issues with post-pain studies, a prospective study instead follows healthy workers, tracking postures, habits, and furniture use to identify correlations between those postures, habits, and furniture uses with developing pain. One recent prospective study reports that "the seated position traditionally recommended for computer users - upper arms perpendicular to the floor, elbows kept at a right angle, forearms parallel to the floor, and the keyboard at or above elbow height and near the edge of the desk or tray_may not be the lowest risk posture" (Marcus et al., 2002, p. 248). They argue that this traditional posture was accepted without epidemiological evidence and that users in their study developed less pain when they used alternative positions. Ultimately, while there may be some agreement regarding the likelihood of certain risk factors for computer-related pain, such as awkward postures or long hours of use, researchers are still calling for more conclusive data regarding the causes of work-related injuries and the effectiveness of preventative measures (Musculoskeletal Disorders and the Workplace, 2001).

While the studies cited above focused on professional office workers who presumably used their computers for more varied activities than writing, it is clear that computer use presents significant risks to physical bodies. Because an injury that develops through any kind of computing will affect writing, and writing at the computer will exacerbate those injuries, these studies present a clear call to writers to attend to the risks of computing. ${ }^{5}$ Unfortunately, we simply don't know everything that causes these pains. They emanate from more than single or simple causes. Following Johnson's (2008) framework, these pains exist in different dimensions of embodiment simultaneously. Addressing the causes or symptoms at only one dimension (e.g.,

${ }^{5}$ Furthermore, some injuries sustained from computing even make writing with pen or pencil difficult, due to pain or numbness in the fingers, wrist, or arm. 
focusing solely on the wrist and keyboards) provides only incomplete solutions. Our ignorance about these causes is hidden partly in our desire to design a "perfect" ergonomic keyboard, desk, or chair. These designs subtly translate our desires for general bodily health to specific programs of posture and movement (cf. Latour, 1999, 1987). These translated programs themselves are not unhealthy, but alone they cannot address the large network of factors that lead writers to injury. From quill, to steel nib pen, to typewriter, to computer keyboard, to split keyboard, writing technologies have assembled a number of motivations into concrete form. But in translating the intention for healthy writing to the material rule of a physical device, things change.

In changing the means of typing from conventional to ergonomic keyboards, the "end" of healthy, injury-free computing has narrowed to the "end" of neutral posture. Neutral posture may be an admirable goal, and ergonomic technology encouraging such posture will likely reduce many symptoms, but this end alone will not result in sustainable writing and computing practices, focusing as it does only on what Johnson would call the ecological body. Additionally, activities that have been comfortable for years may suddenly become painful due to accumulated trauma inside the body. Leaving writers to rely solely on ergonomic objects and their vague senses of comfort (perceptions which themselves can be inaccurate and dangerous - see Alexander [2001/1932]) should not be the standard policy of our profession. As a field and a culture, writing scholars and practitioners cannot afford to wait for science to perfect its study of computing safety, and by extension, writing safety. Instead of waiting for universal recommendations for posture, furniture, or keyboards, our field needs to study how bodies interact with the entire infrastructure of writing, considering the five dimensions of embodiment and integrating the biological with the social and cultural. 
This section has shown that focusing on any isolated element of the infrastructure of composing — or on only one dimension of embodiment — cannot solve the problem of chronic writing pain. Instead it is necessary to address the many dimensions of embodiment. However, our field lacks both a path and a vocabulary for such study and instruction.

\section{Teaching bodies today}

"Concern for how cognition is embodied upends the traditional rhetorical and philosophical insistence that language liberates one's mind from the material conditions of her body. In effect, embodied cognition reasserts how, for all students, denial of the body erases ways not just to be but to think." -Julie Cheville (2001, p. 8)

As suggested in the previous section, technologies are only one piece of the problem of writing pains. More than the technologies themselves, at issue is how we use our bodies as we use those technologies. The physical impact of repetitive technology use is rarely immediate-it begins slowly: we ignore pricks of pain, shake out hand cramps, roll our heads to work out cricks in our necks. Over time, the pricks intensify into pangs, the cramps become numbness or radiated heat, the hunch in our shoulders becomes structural rather than habitual. Admittedly, these issues are unlikely to manifest themselves while our mostly youthful students are in our classes, but it is while they are in our classes, learning to write under pressure, that their bodily practices are likely to become a part of their lifelong writing processes.

Given these circumstances and the likelihood of pain resulting from continued computing, we wonder: Are teachers inadvertently punishing students corporeally by requiring extensive and 
repetitive writing acts without adequate — or any_-somatic training? And by extension, what sorts of somatic training, or bodily awareness teaching, might writing teachers reasonably incorporate into our writing classes? As we describe below, attempts to bring in somatic training from other disciplines or practices have been met by students with, if not outright resistance, then genuine confusion. We provide a new framework that may help both teachers and students better understand writing bodies and how learning and ways of knowing involve all dimensions of embodiment. This research will have two benefits: first, on the bodily habits of the students, but more importantly, second, on our field's understanding of somatic training, its role in the embodied activity of writing, and how it might be integrated into our pedagogy.

Part of our interest in writing bodies/bodies writing emerges from our own experiences of writing in pain. We each, while in our 20 s as graduate students, experienced moderate to significant pain readily linked to our computing and writing tasks. Since our education and subsequent careers depended upon our being able to write- - which of course includes typing and computing - we had to find solutions to our problems. While we each eventually cobbled together tenable prevention-solution strategies involving various technologies, adaptive writing practices, physical exercises, and mind-body coordination training, the processes were messy, expensive, frustrating, time-consuming, and isolating. ${ }^{6}$ There were no ready solutions and certainly no prescriptions for prevention available. It is this absence that we seek to redress.

\footnotetext{
${ }^{6}$ In the hope that it may prove useful to others similarly cobbling together solutions on their own, we provide a
} brief list of the components that make up our own evolving solutions. Second Author has found useful several books regarding somatic instruction, specific software, and a number of physical objects. The books include: Comfort at Your Computer by Paul Linden; Pain Free at Your PC by Pete Egoscue and Roger Gittines; and 8 Steps to a PainFree Back by Esther Gokhale. The software consists mostly of break timers, such as the one available at $<\mathrm{http}$ ://www.workrave.org $>$, which remind users to get up and stretch their hands, wrists, arms, and backs at set 
Second Author used to spend an hour every morning warming his forearms with wet towels and lying on a bed doing gentle stretches. While he found this cumbersome and time-consuming, it was preferable to pain - and Second Author did not reach the level of pain and dysfunction First Author did, which led to her inability to perform everyday tasks like opening jars and buttoning shirts. First Author attempted to solve her repetitive stress injury issues with visits to her physician. Various diseases were ruled out, leaving a diagnosis of tendonitis, but the physician's recommended anti-inflammatories, wrist braces, and physical therapy provided little relief. Recalling a brief introduction to and demonstration of the Alexander Technique from a graduate seminar, she found a local teacher, one of many available_-First Author happened to

intervals. Other software useful for navigating around typing pain, though, would include voice recognition software, such as Dragon Naturally Speaking, and optical character recognition programs, such as OmniPage, which allow for text to be entered through speaking or scanning printed documents. Lastly, the objects include a fullyadjustable keyboard tray (by Humanscale), the Microsoft Natural Elite keyboard (with the number pad hacksawed off to bring the trackball closer), and the Kensington Expert Mouse (which, despite its name, is actually a trackball). First Author also uses the Micosoft Natural Elite keyboard, though without hacksaw modifications, and also uses a break timer (http://prevrsi.sourceforge.net/). First Author first turned to wrist braces, anti-inflammatories, and traditional physical therapy, none of which provided lasting relief, and voice recognition software, which proved more troublesome than helpful. Yoga practice resulted in both relief and flare-ups. Exercises in Elizabeth Montgomery's How to Heal Your Carpal Tunnel Pain Without Surgery relieved symptoms for a time, as did those in The Miracle Ball Method, by Elaine Petrone. First Author found the most relief through Alexander Technique lessons, including an uncompleted stint in a teacher-training course, and has found F.M. Alexander's The Use of the Self of particular use in combination with those lessons. A description of a do-it-yourself component of the Alexander Technique is online at $<$ http://www.jefftessler.com/lie-down.html $>$. Like Second Author, First Author also uses break timers and strategies from Gokhale's book. First author hopes to one day use an adjustable desk such as the Geek Desk (http://www.geekdesk.com/), but its price is currently prohibitive. 
attend graduate school in an area of the country with an extremely high concentration of AT teachers - and arranged a lesson.

That first Alexander lesson was confusing. The lesson did not focus at all on her wrists, or her arms, but on her body as a whole, and on the way she directed her thoughts as she moved. The lesson consisted of the teacher giving a combination of oral directions - with phrases like “think up," or "imagine the tip of your shoulder blade moving back—no, don't move it, just imagine it moving" - and literally hands-on guidance — motions like her clavicle being gently pressed or the back of her neck cupped. She left the lesson feeling taller-indeed, measurements before and after later lessons showed a full half-inch gained, albeit temporarily—more upright; she almost felt as if she were floating. Relief from the injury didn't happen immediately with one AT lesson, but it did happen, and with continued improvement over time, in direct contrast to the previous interventions.

While the Alexander Technique is sometimes described as a way to learn better posture, AT practitioners shy away from this phrase because even hearing or reading it tends to make people stiffen their bodies and raise their chins, adopting a rigid military-style uprightness that differs dramatically from the light and effortless length one's body achieves after a lesson or with sufficient training. The Alexander Technique, as a mind-body method, is difficult, even impossible, to fully explain or understand only through words - it requires a kind of reflective bodily engagement. As Alexander (2001/1932) described it, "knowledge concerned with sensory experience cannot be conveyed by the written or spoken word, so that it means to the recipient what it means to the person who is trying to convey it" (p. 19). ${ }^{7}$ The Technique trains people to

\footnotetext{
${ }^{7}$ See also Sauer's (1998) discussion of the embodied "pit sense" that miners develop through sensory experience rather than linguistic instruction.
} 
think about and use their bodies differently than what has come to feel "natural" or "comfortable"; in doing so it opens up possibilities our culture and habits may have unintentionally closed. It might help to consider here Johnson's definitions of the body in connection with the Alexander Technique. The Alexander Technique works with the body as a biological organism; in doing so, it considers mind-body work as a contextualized process with the ecological body; trains people to reconsider their habitual assumptions about the phenomenological body, enhances attention to the ways the social body develops, how the body forms habits through observation, touch, and association, and can form new habits in the same way; and invites examination of how each of these is affected by or embedded within the cultural body. ${ }^{8}$

Given First Author's experiences writing in pain and her subsequent discovery of the value of somatic training, she felt a responsibility to begin to address bodies in her writing classroom to help students avoid future pain. Yet her efforts to include somatic learning along with the

\footnotetext{
${ }^{8}$ We are not arguing that writing teachers teach the Technique itself in writing classes, but we believe that the
} Alexander Technique and other mind-body approaches offer principles and practices that could, in the words of an early reader of this article, be "mapped onto composition theory to yield a more holistic approach to writing instruction." One such principle from AT is that of "inhibition." For F.M. Alexander, the Australian actor who developed the Technique to overcome a career-threatening problem with hoarseness while speaking, inhibition meant not the Freudian sense of unconscious repression, but rather a conscious pause before "doing" [e.g., moving]. We might apply the possibilities for inhibition specifically to writing: we might encourage students to take a conscious pause before beginning to type — not only to assess possible physical alignments or environmental choices that might be detrimental to the writing process, but also to quell the habitual (and often negative) thoughts that can accompany such a beginning. Practicing "inhibition" in this sense — and it would take practice—could reduce both physical writing-related pain and the emotional anxiety or pain so many associate with writing. 
more traditional conceptual learning met with mild resistance and confusion. In spring and fall 2008 First Author taught "Scientific and Technical Writing," a general education course at her university. Because technical writers commonly suffer from repetitive stress injuries such as carpal tunnel syndrome and tendonitis, First Author chose that class for a somatic training experiment. First Author's approach to incorporating somatic awareness into a writing class already full of "content" was to double-up, to elaborate a fairly standard technical writing assignment_- "revise these directions"—-into a project asking for multi-layered learning. She chose the book The Miracle Ball Method, by Elaine Petrone (2003). The book consists of descriptions of exercises that involve resting different body parts on an inflated ball about six inches in diameter, relying on gravity and relaxation to produce bodily change. She hoped that students' minds and bodies would be doubly engaged, that lessons about the clarity of instructions, layout, and page design would be enhanced by the embodied experiences of working with the book's exercises, and vice versa. She hoped that both sets of lessons would be the stronger for their reliance upon one another. Having used The Miracle Ball Method in her search for solutions to her pain, First Author thought students would find this text relatively accessible — its methods more readily translatable solely through words than the Alexander Technique, for example — and thought the book's poor design and sometimes unclear instructions would provide students with a useful revision and redesign experience.

First Author assigned The Miracle Ball Method because she wanted students to: 1) think about their bodies in relation to their writing as a way of preventing future injuries; 2) learn ways to relax their bodies, which she believed would reduce their stress and help with their writing; and 3) consider how issues of layout and page design, in addition to content, could affect one's use of a text. To give the students exposure to body information and practice over time, First 
Author assigned small sections of Petrone's book throughout the semester, encouraging students to test out exercises. The most explicit lesson came during a unit whose major assignment was to write a proposal for and design a sample chapter of a ghostwritten new edition of that book.

Students' work and reactions suggest that they learned the page design and instructionwriting lessons, but the bodily components were considered separate, superfluous, or simply "nice." The first semester, a student tried the exercises on a morning when he was suffering from a hand cramp after having fallen asleep holding his cell phone; while he seemed frustrated that there was no exercise specifically for that type of cramp, he remarked that the overall bodily stress reduction had seemed to help his hand. A few students had similarly positive, albeit vague reactions, but no students felt a connection between the exercises and their writing. It's possible that students' work was actually enhanced by their physical encounters with the book, but that is a possibility they didn't consider and we can't demonstrate. It's also possible that students struggled to put into words what they had learned about and through their bodies.

These benefits aside, however, students found the incorporation of embodied activity into the writing class to be, at best, tangential to the work of writing. One student suggested on Ratemyprofessors.com that First Author's hopes were somehow disingenuous, writing: “[the professor] makes you buy an [sic] self-help book that comes with exercise balls to help your stress, then assigns homework that tells you to do the exercises." The fact that First Author assigned the exercises in the required book may have seemed to negate any genuinely helpful instructional intent. In a culture where work (homework or other) and perceived stress are deeply entwined, to suggest that work might ameliorate rather than heighten stress would be incomprehensible. It is this harmful correlation that we seek to address; if we can find a way to 
write/type/work without undue stress — whether bodily, psychological, or both —we can have longer, healthier writing careers.

In retrospect we can see that because of the utter absence of somatic instruction in our educational system (and limited somatic awareness in our society), students truly had no framework for understanding the potential value of bodily learning in a writing class. Their understanding of coursework likely only extended to mental learning, rather than any embodied understandings, and First Author did not then know of Johnson's framework to help students see ways of considering the body. Thus, the somatic awareness components likely seemed to students disconnected from the rest of the course. Also, First Author's long-term experiences with pain and somatic training likely led her to start off with goals a bit too ambitious (much like a new teacher initially attempting to teach a subject at a depth closer to where she is than where her students may be). While this particular experiment did not have the desired result of students becoming able and willing to more carefully tend to their writing bodies, we believe there are ways to bring about this change, and that our field can and should work to find, articulate, and refine them. While it will certainly be a challenge to convince young students (who are notoriously blasé about the possible frailty of their bodies) that taking care of their bodies might be important, and particularly important to them as writers, we think it is both possible and imperative that writing teachers begin to do so.

\section{Teaching bodies in the past}

For $21^{\text {st }}$ century students, it seems strange that a writing teacher might ask them to consider their bodies. Students expect that kind of attention in a dance or physical education class, but not in a writing course. Not that long ago, however, it would not have been unusual for some kinds of writing teachers, such as handwriting or typewriting teachers, to offer bodily advice, 
instruction, or even prescription. As Emma Harrison Myers (1963) suggests in The Whys and Hows of Teaching Handwriting, “[j] ust as there is good 'form' for the baseball player, or the golfer, or the artist, or the stenographer, so there is good 'form' for efficient handwriting" (p. 29). Myers goes on to list such concerns as properly fitted furniture, bodily ease, posture, lighting, and materials placement. This is no small list of important elements outside the shaping of letters; the list suggests that at least some handwriting teachers were addressing writing as part of an infrastructure, not simply as isolated and rote bodily instruction. Further, today's ergonomics advice echoes her list, which suggests that inattention to these issues is of concern to writers at any age, in any era.

While aspects of handwriting and typewriting instruction are certainly outdated or rightly out of favor (for example, the notion that one's intelligence or mental fitness is determined by the neatness of one's "hand"), elements of the bodily instruction offered by these instructional ancestors, a strand of instruction offered well into the 20th century, could serve as inspiration for contemporary efforts. For example, typewriting handbooks, as part of their goal of enhancing typing speed and accuracy, often included an emphasis on posture. In Techniques for Teaching Typewriting, for example, Jane Clem (1955) emphasizes that students must be taught correct posture:

Correct Posture. Efficient control cannot be exercised if the typist does not assume a bodily position that will permit his nerves and muscles to function freely. If the expert does not feel right as he sits before his machine, he knows he cannot type right. (p. 225) Clem's emphasis on a single "correct posture" is problematic in its rigidity and seeming simplicity and mainly suited for the particular typewriting technologies of the past. But her notion of the body "functioning freely" recalls First Author's experience with the Alexander 
Technique, and meshes well with a body-mindful writing practice in our modern context. While we want to avoid Clem's focus on one particular "correct" posture and move to a more fluid understanding of safe and sustainable bodily interactions with a variety of technologies, her assertion that bodily awareness is important for writing accuracy and for long-term functionality remains salient.

Some modern educators, too, explicitly note the necessity of "keystroking technique, reliance on the sense of touch instead of vision, and correct body posture" for the "prevention of keyboarding-related health problems" (Wiseman, 2000, p. 3). However, our review of recent studies pertaining to current typewriting or keyboarding instruction suggests that an awareness of bodily use, even at the level of ergonomics we'd like to push beyond, is not prevalent in typewriting or keyboarding instruction today. Instead, research coalesces around topics such as how and when to teach keyboarding (Ash, 2006; Collett, 2008), work that makes little or no mention of bodies or posture. While we do not advocate a reversion to a schoolmarm-ish approach to posture, and would not even suggest to students that they necessarily avoid using laptops on beds, in cars, or in other spaces that would be incomprehensible to a typewriting teacher, we do suggest working with students to explore and demonstrate the injury-preventative benefits of more ergonomically-arranged space, of regular breaks and stretches, of more considered bodily positioning. ${ }^{9}$

Given the great diversity of local writing infrastructures, we will not prescribe any one particular method or school of somatic instruction, or even particular kinds of physical activity that should be incorporated into writing instruction. Instead, we encourage writing teachers to

\footnotetext{
${ }^{9}$ In addition to injury-prevention, such habits appear to have potential for further benefits, such as a more enjoyable writing process and increased productivity (Boice, 2000).
} 
use Johnson's multidimensional definition of embodiment as a heuristic for exploring the embodied activity of writing with students. Computers and writing scholars are likely already adept at examining with students the cultural assumptions and beliefs embedded in contemporary technologies. These discussions can be extended to include the other ways these technologies affect embodied activity. For example, a unit on the cultural logic of efficiency and progress embedded in contemporary ideologies of technology might extend into an examination of how those cultural logics affect physical bodies (e.g., through keyboard development or requirements to type for hours without breaks).

\section{Writing as a body-mind practice}

Good writing practices have too often been assumed to involve suppressing attention to the body and its interactions with writing tools. After all, or so it is imagined, how can one write well when struggling to properly manipulate a pencil or hunting and pecking on the keyboard? As this article has shown, though, there are dangers in writers' desire to transcend their bodies and the physical interface of writing. In addition to initiating discussion of how the field of rhetoric and composition might positively intervene in the epidemic of repetitive stress injuries, we also hope that returning attention to the body's positioning and movement in relationship to technologies of writing will create a better understanding of the possibilities and effects of the full range of interactions between bodies and objects.

Writing teachers are always already training bodies to write, whether offering explicit instruction or not. But by ignoring student writers' bodies, teachers may be missing opportunities to help writers develop habits and mind-body awareness that can protect them from physical damage, up to and including diminished strength, loss of sensation, and chronic, debilitating pain. As the field works to consider ways of integrating somatic training as a part of writing 
instruction, it is not enough to simply replace a few elements of the writing infrastructure, such as pieces of furniture (a keyboard, a chair, a desk) or types of software. Instead, the entire infrastructure must be considered holistically by attending to each of the five dimensions of embodiment together. In the absence of good and clear evidence about how people can write in healthy ways, we must not allow any one component of that infrastructure - such as technologies — to be the sole actor concerned with our behaviors. Writing teachers must be concerned and must teach students to concern themselves with their own physical writing practices. In other words, we must care for our students and the well-being of their bodies as they write. Such a position resonates with a discipline long attuned to the care of students individually and collectively.

To use the language of DeVoss, Cushman, and Grabill (2005), investigating the issue of writing pain has led us to address the infrastructure of composing. Devoss et al.'s broad definition of this term, where "infrastructure is more than material, is never static, and is always emerging” (p. 22), makes room for a balanced attention to bodies and technologies as they are involved in writing processes. As we have argued, writing pain is not, as might be assumed, caused solely by a specific keyboard design, a specifically flawed body, or one particular posture. Instead, these pains are a result of certain infrastructures, the always emerging network of actors that participate in composition — keyboards and furniture play a role, surely, but also our bodily practices, attitudes, and tasks. And yet particular technologies, practices, and attitudes can, unfortunately, prevent or suppress mindfulness of risks to the body. Rather than advocating for a particular ergonomic keyboard, chair, bodily training method, or stretching regimen, although these components will surely be useful for many writers, we point instead to a more 
general mindfulness of the body as the common thread running through many schools of somatic training as well as ergonomic advice.

We define mindfulness of the body as a depth of attention within each of the multiple dimensions of embodiment Johnson delineates, as well as a breadth of attention across them. For example, rather than focusing solely on the pain in one's wrist after typing, a body-mindful writer might seek out other sources of physical discomfort in the body that could be connected (e.g., hunched shoulders, cramped neck). And extending beyond the biological body, a bodymindful approach might entail exploring alternative postures and mindful approaches that provide feedback on causes and solutions to the pain (e.g., Alexander Technique, yoga) and reflecting on the variable effects of cultural patterns of body positioning.

Although we are primarily focused in this piece on mindfulness of the body to prevent injury, more general models of mindfulness as "reflective awareness" have been found to be valuable for writers, indicating that other valuable lines of inquiry may develop from the approach we are advocating. In Advice for New Faculty Members, psychologist Robert Boice explicitly brings mindfulness and writing together. He asserts that "[i]ndications that mindfulness helps writers write are anything but new, just uncommon and usually unknown” (2000, p. 107). While "mindfulness" suggests a "calm attentiveness to the present moment," and "often aims consciousness away from thinking and external doing," "writing" is "usually portrayed as hard work that strains the intellect and overstimulates the emotions" (p. 106). Boice, in other words, advocates becoming mindful of the benefits of not practicing writing as hard work. Boice's advice resonates with James Moffett's (1982) argument that practicing meditation allows writers to think and write better. The benefits of bringing writers' bodies and minds together, then, go 
far beyond injury prevention or pain management; mindfulness practices also benefit the writing process and product.

Our focus on the infrastructure of composing evolves Fleckenstein's notion of somatic mind, and rests on also bringing the mind to the workings of the body—-for the benefit of both mind and body. The phrase "embodied knowledge," also encompasses these mind-body emphases, referring to knowing the body through the mind and knowing the mind through the body —in much the same way that John Dewey uses the notion of the "body-mind": "not simply the acknowledgement of the sensory input that goes to the brain, but it is based upon the interaction of the subject within a complex and challenging environment" (Davidson, 2004, p. 198). We believe that writers' bodies and minds work best when consciously linked, and that this linking necessitates explicit study and instruction in our field at the college level. Studies with a multiple intelligence focus carried out at the elementary school level have found positive correlations between changed body positions and furniture and improved positive student learning and experiences. For example, stand-up desks, exercise balls instead of chairs, and nontraditionally arranged classrooms change the relationship of children's minds and bodies and give them the opportunity to "focus better on their work" (Saulny, 2009). As one teacher explains: "The whole theory with the brain is that when your body's engaged, your brain's engaged. I call it actively sitting. They're maybe moving their legs a little, wiggling some. But their upper body, they're focused on writing, on the teacher. It really works" (Wyatt, 2009). Such initiatives at the elementary level are few, but promising, and while we discovered no such initiatives at higher levels of education, we believe they are both possible and important.

Rather than suggesting a specific kind of somatic practices training for teachers and scholars in our field to adopt, our hope is that this article has emphasized the value of approaching 
embodiment through multiple dimensions - engaging the physical, lived experiences of writers with social and cultural understandings of embodiment. Such work, we believe, is necessary both to prevent writing-related pain and to enhance the field's ongoing research into writing processes and practices. 
Works Cited

Alexander, F.M. (2001). The Use of the Self. London: Orion.

Ash, Yvonne M. (2006). The Timeliness of Keyboarding Instruction as Perceived by Middle School Business Instructors in an Urban School District (Unpublished dissertation). Nova Southeastern University.

Baron, Dennis. (2000). From pencils to pixels: The stages of literacy technologies. In Gail E Hawisher \& Cynthia L Selfe (Eds.), Passions, pedagogies, and 21st century technologies (pp. 15-33). Logan, UT: Utah State University Press.

Birmingham, Elizabeth. (2004). Another Fine Mess: The Pregnant Body and the Discipline of the Line. WOE: Writing on the Edge, 14(2), 95-109.

Boice, Robert. (2000). Advice for New Faculty Members: Nihil Nimus. Boston: Allyn and Bacon. Brandt, Deborah. (2001). Literacy in American lives. Cambridge: Cambridge University Press. Brewer, Shelley, Van Eerd, Dwayne, Amick III, Benjamin C, Irvin, Emma, Daum, Kent M, Gerr, Fred, Moore, J. Steven, et al. (2006). Workplace interventions to prevent musculoskeletal and visual symptoms and disorders among computer users: A systematic review. Journal of Occupational Rehabilitation, 16, 325-358.

Brodkey, Linda. (1996). Writing Permitted in Designated Areas Only. Minneapolis: University of Minnesota Press.

Brueggemann, Brenda Jo, White, Linda Feldmeier, Dunn, Patricia A., Heifferon, Barbara A., \& Johnson Cheu. (2001). Becoming Visible: Lessons in Disability. College Composition and Communication, 52(3), 368-398. doi:10.2307/358624

Chamberlain, David B. (1998). Babies don't feel pain. In Robbie Davis-Floyd \& Joseph Dumit (Eds.), Cyborg Babies: From Techno-Sex to Techno-Tots (pp. 168-192). New York, NY: Routledge. 
Cheville, Julie. (2001). Minding the Body: What Student Athletes Know About Learning.

Portsmouth, NH: Boynton/Cook-Heinemann.

Clem, Jane. (1955). The techniques of teaching typewriting, . New York: The Gregg Pub. Co.

Collett, Margie. (2008). An Analysis of Eighth Grade Keyboarding Instruction at Pepin Area School (Unpublished Master's Thesis). University of Wisconsin-Stout.

Cranz, Galen. (1998). The Chair: Rethinking Culture, Body, and Design (1st ed.). New York: W.W. Norton.

Crowley, Sharon. (2002). Body studies in rhetoric and composition. In Gary A Olson (Ed.), Rhetoric and composition as intellectual work (pp. 177-187). Carbondale: Southern Illinois University Press.

Davidson, Judith. (2004). Embodied Knowledge: Possibilities and constraints in Art Education and Curriculum. In Liora Bresler (Ed.), Knowing Bodies, Moving Minds: Towards an Embodied Teaching and Learnin (pp. 197-212). Dordrecht, Netherlands: Kluwer Academic Publishers.

Dembe, Allard E. (1996). Occupation and Disease: How Social Factors Affect the Conception of Work-Related Disorders (1st ed.). Yale University Press.

DeVoss, Dánielle Nicole, Cushman, Ellen, \& Grabill, Jeffrey T. (2005). Infrastructure and composing: The when of new-media writing. College Composition \& Communication, $57(1), 14-44$.

Egan, Kieran. (2004). Endorsements. In Liora Bresler (Ed.), Knowing Bodies, Moving Minds: Towards an Embodied Teaching and Learning. Dordrecht, Netherlands: Kluwer Academic Publishers. 
Fleckenstein, Kristie S. (2003). Embodied Literacies: Imageword and a Poetics of Teaching. Carbondale: Southern Illinois University Press.

Fleckenstein, Kristie S. (1999). Writing bodies: Somatic mind in composition studies. College English, 61(3), 281-306.

Gerard, Michael J., Jones, Stephen K., Smith, Leo A., Thomas, Robert E., \& Wang, Tai. (1994). An ergonomic evaluation of the Kinesis Ergonomic Computer Keyboard. Ergonomics, 37(10), 1661-1668. doi:10.1080/00140139408964943

Gere, Anne Ruggles. (1994). Kitchen Tables and Rented Rooms: The Extracurriculum of Composition. College Composition and Communication, 45(1), 75-92. doi: $10.2307 / 358588$

Gerr, Fred, Marcus, Michele, \& Monteilh, Carolyn. (2004). Epidemiology of musculoskeletal disorders among computer users: Lesson learned from the role of posture and keyboard use. Journal of Electromyography and Kinesiology, 14, 25-31.

Gerr, Fred, Marcus, Michele, Ensor, Cindy, Kleinbaum, David, Cohen, Susan, Edwards, Alicia, Gentry, Eileen, et al. (2002). A prospective study of computer users: I. Study design and incidence of musculoskeletal symptoms and disorders. American Journal of Industrial Medicine, 41, 221-235.

Haas, Christina, \& Witte, Stephen P. (2001). Writing as an embodied practice: The case of engineering standards. Journal of Business and Technical Communication, 15(4), 413457.

Hamilton, Audra G., Jacobs, Karen, \& Orsmond, Gael. (2005). The prevalence of computerrelated musculoskeletal complaints in female college students. Work, 24(4), 387-394. doi:Article 
Harris, Judith. (2003). Signifying Pain: Constructing and Healing the Self Through Writing. SUNY series in psychoanalysis and culture. Albany: State University of New York Press. Hawhee, Debra. (2004). Bodily Arts: Rhetoric and Athletics in Ancient Greece (1st ed.). Austin, TX: University of Texas Press.

Hayles, N. Katherine. (1999). How we became posthuman: Virtual bodies in cybernetics, literature, and informatics. Chicago, IL: University of Chicago Press.

Honeycutt, Lee. (2003). Researching the use of voice recognition writing software. Computers and Composition, 20, 77-95.

Hudson, John. (2007, May). Silent Readers, Silenced Readers: LGBT Student Perceptions of LGBT Representation in Composition Reader (Unpublished dissertation). University of Illinois at Urbana-Champaign.

Jain, Sarah S. Lochlann. (2006). Injury: The politics of product design and safety law in the United States. Princeton, N.J.: Princeton University Press.

Johnson, Mark. (2008). What Makes a Body? The Journal of Speculative Philosophy, 22(3), 159169. doi: $10.1353 /$ jsp. 0.0046

Katz, Jeffrey N., Amick III, Benjamin C, Carroll, Barbara B., Hollis, Christine, Fossel, Anne H., \& Coley, Christopher M. (2000). Prevalence of upper extremity musculoskeletal disorders in college students. The American Journal of Medicine, 109(7), 586-588.

Kaufman, Rona. (2007). Running in Place: The Personal at Work, in Motion, on Campus, and in the Neighborhoo. In Jennifer Sinor \& Rona Kaufman (Eds.), Placing the Academy: Essays on Landscape, Work, and Identity. Logan, UT: Logan Utah State University Press. 
Kazan, Tina. (2007). Braving the Body: Embodiment and (Cyber-)Texts. In Joe Lockard \& Mark Pegrum (Eds.), Brave New Classrooms: Democratic Education and the Interne (pp. 25170). New York, NY: Peter Lang Publishing.

Latour, Bruno. (1987). Science in action: How to follow scientists and engineers through society. Cambridge, MA: Harvard University Press.

Latour, Bruno. (1999). Pandora's hope: Essays on the reality of science studies. Cambridge, MA: Harvard University Press.

Latour, Bruno. (2002). Morality and technology: The end of the means. Theory, Culture \& Society, 19(5/6), 247-260.

Mahiri, Jabari, \& Godley, Amanda. (1998). Rewriting Identity: Social Meanings of Literacy and “Re-visions" of Self. Reading Research Quarterly, 33(4), 416-433. doi:10.1598/RRQ.33.4.4

Malinowitz, Harriet. (1995). Textual Orientations: Lesbian and Gay Students and the Making of Discourse Communities. Portsmouth, NH: Boynton/Cook Publishers.

Marcus, Michele, Gerr, Fredric, Monteilh, Carolyn, Ortiz, Daniel J, Gentry, Eileen, Cohen, Susan, Edwards, Alicia, et al. (2002). A prospective study of computer users: II. Postural risk factors for musculoskeletal symptoms and disorders. American Journal of Industrial Medicine, 41, 236-249.

Mauss, Marcel. (2007). Techniques of the Body. In Margaret Lock \& Judith Farquhar (Eds.), Beyond the Body Proper: Reading the Anthropology of Material Life (pp. 50-68). Durham NC: Duke University Press.

Moffett, James. (1982). Writing, Inner Speech, and Meditation. College English, 44(3), 231-246. doi: $10.2307 / 377011$ 
Mortensen, Peter. (1999). Figuring Illiteracy: Rustic bodies and Unlettered minds in Rural America. In Jack Selzer \& Sharon Crowley (Eds.), Rhetorical Bodies. Madison, Wis: University of Wisconsin Press.

Musculoskeletal Disorders and the Workplace. (2001). . Washington D.C.: National Research Council and Institute of Medicine.

Myers, Emma Harrison. (1963). The Whys and Hows of Teaching Handwriting. Columbus: Zaner-Bloser Company.

Owens, Kim Hensley. (2010). “Look Ma, No Hands!”: Voice-Recognition Software, Writing, and Ancient Rhetoric. Enculturation, 7. Retrieved from http://enculturation.gmu.edu/look-ma-no-hands

Pennebaker, James W. (1990). Opening up: The Healing Power of Confiding in Others (1st ed.). New York: W. Morrow.

Petrone, Elaine. (2003). The Miracle Ball Method: Relieve Your Pain, Reshape Your Body, Reduce Your Stress [2 Miracle Balls Included] (Book and Access.). Workman Publishing Company.

Pogue, David. (2006, July 20). Like Having a Secretary in Your PC. The New York Times. Retrieved from http://www.nytimes.com/2006/07/20/technology/20pogue.html

Price, Margaret. (2007). Accessing Disability: A Nondisabled Student Works the Hyphen. College Composition and Communication, 59(1), 53-76.

Prior, Paul, \& Shipka, Jody. (2003). Chronotopic lamination: Tracing the contours of literate activity. In Charles Bazerman \& David Russell (Eds.), Writing selves/writing societies (pp. 180-238). Fort Collins, CO: The WAC Clearinghouse and Mind, Culture, and Activity. 
Rempel, David. (2008). The split keyboard: An ergonomics success story. Human Factors, $50(3), 385-392$.

Rempel, David, Barr, Alan, Brafman, David, \& Young, Ed. (2007). The effect of six keyboard designs on wrist and forearm postures. Applied Ergonomics, 38, 293-298.

Reynolds, Nedra. (2004). Geographies of Writing: Inhabiting Places and Encountering Difference. Carbondale: Southern Illinois University Press.

Robertson, Michelle, Amick III, Benjamin C., DeRango, Kelly, Rooney, Ted, Bazzani, Lianna, Harrist, Ron, \& Moore, Anne. (2009). The effects of an office ergonomics training and chair intervention on worker knowledge, behavior and musculoskeletal risk. Applied Ergonomics, 40(1), 124-135.

Sauer, Beverly. (1998). "Embodied knowledge: The textual representation of embodied sensory information in a dynamic and uncertain material environment. Written Communication, 15(2), $131-169$.

Saulny, Susan. (2009, February 25). Students Stand When Called Upon, and When Not. The New York Times. Retrieved from http://www.nytimes.com/2009/02/25/us/25desks.html Scarry, Elaine. (1985). The Body in Pain: The Making and Unmaking of the World (1st ed.). Oxford University Press, USA.

Selzer, Jack, \& Crowley, Sharon (Eds.). (1999). Rhetorical Bodies. Madison, Wis: University of Wisconsin Press.

Tenner, Edward. (1997). Why things bite back: Technology and the revenge of unintended consequences. New York: Vintage Books.

Tenner, Edward. (2003). Our own devices: The past and future of body technology. New York: Alfred A. Knopf. 
Tittiranonda, Pat, Rempel, David, Armstrong, Thomas, \& Burastero, Stephen. (1999). Effect of four computer keyboards in computer users with upper extremity musculoskeletal disorders. American Journal of Industrial Medicine, 35, 647-661.

Wilson, James C., \& Lewiecki-Wilson, Cynthia. (2001). Disability, Rhetoric, and the Body. In James C. Wilson \& Cynthia Lewiecki-Wilson (Eds.), Embodied Rhetorics: Disability in Language and Culture (pp. 1-26). Carbondale, IL: Southern Illinois University Press.

Wiseman, Gary. (2000, May). Keys at Their Fingertips: A Study Supporting Development of a Resource Package For the Teaching of Touch-Keyboarding Skills in Upper Elementary Classrooms Equipped with Portable Keyboard (Unpublished Master's Thesis). Walden University.

Wyatt, Kristen. (2009, March 4). No Chairs: Students “Get the Wiggles Out” on Exercise Balls. USA Today. Retrieved from http://www.usatoday.com/news/education/2009-03-07-classchairs_N.htm 